\title{
Diferencia en campo: prácticas económicas y Amefricanidade de las Baianas de Acarajé contra FIFA
}

Larissa da Silva-Araujo*

\footnotetext{
Magíster en Derechos Humanos y Ciudadanía. Investigadora del Instituto Anis de Bioética, Derechos Humanos y Género y Consultora PNUD, Ministerio de Justicia, Brasil. orreo electrónico: larissacarel@gmail.com
}

Recibido: 17 de enero del 2016

Aceptado: 31 de mayo del 2016

Cómo citar este artículo: Da Silva-Araujo, L. (2016). Diferencia en campo: prácticas económicas y Amefricanidade de las Baianas de Acarajé contra FIFA, 24(109), XX-XX. doi: 10.16925/co.v24i109.1505

\section{Resumen}

Propósito: el artículo presenta algunas reflexiones resultantes de una investigación sobre la disputa entre baianas de acarajé en contra de la FIFA, organismo rector del futbol mundial. Descripción: con la realización del Mundial de Fútbol de la FIFA en el 2014, se implementó en Brasil el "modelo de desarrollo por mega eventos" que resultó en la violación de derechos humanos de muchos brasileros, entre ellos, las baianas de acarajé. Esas mujeres, trabajadoras callejeras a las que se les impidió trabajar en las llamadas "zonas de exclusión de la FIFA", resistieron para que su oficio, actividad realizada hace siglos, fuera respetado como forma económica autónoma. Punto de vista: para desafiar al frente estatal-empresarial que se estableció en el país, realizaron varias estrategias de lucha que fueron de la negociación a la acción directa. Conclusiones: a partir de los hallazgos de la investigación en campo, según una perspectiva interseccional y descolonial, presento algunos aspectos de esa disputa y las características de la racionalidad económica de las baianas de acarajé.

Palabras clave: Amefricanidade, baianas de acarajé, decolonialidad, desarrollo, FIFA, racionalidad económica. 


\title{
Differences in the field: economic practices and Amefricanity of Bahian Acarajé women struggling against FIFA
}

\begin{abstract}
Purpose: This article presents certain reflections resulting from an investigation into the dispute between Bahian Acarajé women and FIFA, the governing body of world football. Description: With the hosting of the FIFA World Cup in 2014, the "mega-event development model" was implemented in Brazil. This model resulted in the violation of the human rights of many Brazilians, including the Bahian Acarajé women. These women-street workers who were prevented from working in so-called "FIFA exclusion zones" - resisted to have their centuries-old trade be respected as an autonomous economic activity. Viewpoint: In order to challenge the front of state-owned enterprises that was established in the country, the women engaged in various strategies of struggle spanning from negotiation to direct action. Conclusions: Based on the research findings in the field, I present some aspects of the dispute and the characteristics of the economic rationale of the Bahian Acarajé women from an intersectional and decolonial perspective.
\end{abstract}

Keywords: Amefricanity, Bahian Acarajé women, decoloniality, development, FIFA, economic rationale

\section{Diferença em campo: práticas econômicas e Amefricanidade das Baianas de Acarajé contra a FIFA}

\section{Resumo}

Propósito: este artigo apresenta algumas reflexões resultantes de uma pesquisa sobre a disputa entre baianas de acarajé contra a FIFA, entidade máxima do futebol mundial. Descrição: com a realização da Copa do Mundo de Futebol da FIFA em 2014, implementou-se no Brasil o "modelo de desenvolvimento por mega eventos" que resultou na violação de direitos humanos de muitos brasileiros, entre eles, as baianas de acarajé. Essas mulheres, trabalhadoras de rua que foram impedidas de trabalhar nas chamadas "áreas de exclusão da FIFA", resistiram para que seu trabalho, atividade realizada há séculos, fosse respeitado como forma econômica autônoma. Ponto de vista: para desafiar a frente estatal-empresarial que se estabeleceu no país, realizaram várias estratégias de luta que foram da negociação à ação direta. Conclusões: a partir das descobertas da pesquisa de campo, de acordo com uma perspectiva interseccional e descolonial, apresento alguns aspectos dessa disputa e as características da racionalidade econômica das baianas de acarajé.

Palavras-chave: Amefricanidade, baianas de acarajé, decolonialidade, desenvolvimento, FIFA, racionalidade econômica.. 


\section{Introducción}

Desde que Brasil fue electo para ser la sede de algunos megaeventos -el Mundial de Fútbol de la FIFA en el 2014 y los Juegos Olímpicos del 2016 en Río de Janeiro- una serie de grupos, colectivos y movimientos sociales se articularon para impedir violaciones de derechos humanos. Eso porque, con el discurso del "legado", fue impulsado en el país un modelo de desarrollo propio de megaeventos que resultó en diversas violaciones de derechos, como al de la vivienda adecuada, al trabajo, al consumidor, al de los niños y adolescentes, etc. Uno de esos grupos fue el grupo de baianas de acarajé, mujeres callejeras, vendedoras de la comida llamada "acarajé", que articuladas por la Asociación de Baianas de Acarajé y Mingau (АВАM), lucharon directamente contra las prohibiciones de la FIFA.

Involucrada en la articulación de afectados por el modelo de desarrollo de los megaeventos, me dediqué a estudiar la lucha de las baianas de acarajé contra la FIFA. En este artículo, presento alguno de los hallazgos más importantes de esa investigación, relacionados principalmente con la comprensión de la economía practicada por las baianas de acarajé. El texto está dividido en cinco grandes partes que se complementan, y tratan de manera general los aspectos relacionados con la definición del oficio de las baianas de acarajé; del conflicto entre las baianas, la FIFA y el Estado (llamado de frente-estatal empresarial), y de los resultados de mi experiencia en campo con ellas. Al final, destaco algunas reflexiones sobre la racionalidad económica que constituye su oficio.

\section{Baiana de acarajé: oficio ancestral de mujeres negras}

Antes de todo es necesario explicarles los términos más comunes que van a ser utilizados en este artículo. El término "baianas de acarajé" es una categoría que los antropólogos suelen utilizar para "nativa". Se refiere al oficio de cocineras y vendedoras callejeras, realizado por mujeres, generalmente negras, afrodescendientes y que profesan el candomblé, una religión del universo afrobrasileño. Aunque haya hombres que realicen el oficio con frecuencia, se denomina el oficio con el género lingüístico femenino porque ellas son la mayoría de las personas que realizan ese trabajo.

Alrededor de las baianas, compartiendo con ellas ciertos espacios, principalmente el ambiente familiar y religioso, hay otras mujeres que integran sus redes de producción y solidaridad. Son las "baianas de receptivo", mujeres que actúan como baianas de acarajé en ceremonias de bendición religiosa, como lavado de escaleras, baianas auxiliares, aprendices que ayudan en la cocción o en la venta, y otras mujeres que, por ejemplo, cosen el richilieu, tela delicada hecha a mano, utilizada en las ropas típicas de las baianas de acarajé.

Generalmente, las baianas llevan una ropa típica, un tabuleiro (tabla con las comidas, acarajé, vatapá, caruru, bolinho de estudiante), que se carga en la cabeza o se pone sobre piernas de madera, lo que forma una mesa, utensilios de cocción y una masa fresca de acarajé para freír (en el caso en que hagan la comida instantáneamente). Las baianas, que no venden acarajé en las playas (que cargan el tabuleiro en la cabeza), se establecen en lugares fijos en las calles, los llamados "puntos". Una baiana tiene la costumbre de respetar el punto de la otra, es decir, no llega más temprano y lo toma para sí misma, por ejemplo. Una expresión utilizada para decir que una mujer realiza el oficio de la baiana de acarajé es "se sienta en el tabuleiro".

En el caso de esa investigación, las autodefiniciones de baiana de acarajé adquieren sentidos y usos que dependen de los contextos de habla de las baianas. En estos dichos, identifiqué autodefiniciones que pueden contribuir para nuestra comprensión de lo que es baiana de acarajé: "mujer", "negra", "trabajadora", "autónoma". Pude observar que hay una complejidad en torno al sujeto "baiana de acarajé" y no es el propósito de ese artículo encuadrarlas en una u otra definición atribuida en cada designación. Sin embargo, sobre eso merece destaque la siguiente afirmación:

El acarajé se encuentra, en su trayectoria histórica, en el cruce entre mercancía palpable y consumible y un complejo sistema simbólico religioso que permea los cultos afrobasileros, que lo construyeron como una ofrenda, sin buscar una separación o una especialización que pudiera diferenciar el plan mercadológico del plan sacro (Torres, 2007, p. 240).

En ese sentido, al buscar comprender ese cruce, aprendí en el memorial de las baianas de acarajé, espacio museológico sobre el oficio, ubicado en la ciudad de Salvador, que las baianas de acarajé que son de la religión candomblé hacen el acarajé en ofrenda a Oiá o Iansã y, generalmente, son aquellas personas cuyo ori (cabeza) es guiado por ese orixá. Así, el 
acarajé es considerado un alimento votivo, ya que es un alimento producido no solo para la venta y subsistencia de las baianas que lo hacen, sino que también puede adquirir una función simbólico-religiosa cuando son hechos como una "obligación de santo".

En efecto, hay baianas de acarajé que hacen el acarajé para que sean vendidos en las calles, con la finalidad de sostener sus familias, y baianas que lo hacen para cumplir con sus obligaciones como hijas de Iansã, contribuyendo con el sostenimiento de sus comunidades de terrero (comunidades de las casas de candomblé), ya sea porque los miembros de la comunidad consumen el alimento, sea porque ellas obtienen renta de la venta en las calles y comparten con sus comunidades. Están también aquellas que desempeñan los dos papeles de madre de familia y de hija de santo, de manera que el acarajé tiene una función central en sus vidas (Torres, 2007; Santos, 2013).

En una de las paredes del memorial estaba la siguiente inscripción: "Dice el itã (leyenda): Fue Oiá o Iansã, que también es Santa Bárbara, la mujer que enseñó a las otras mujeres cómo hacer el acará, nuestro acarajé. Empezó entonces el oficio, el trabajo para que ellas pudieran criar sus hijos" (tradición oral).

Según los mitos sobre el acarajé, este era una pelota de fuego hecha por Oxum y comida por Xangô. Oxum preparaba el alimento en secreto y entregaba la olla tapada a Iansã, que así la llevaba en la cabeza para Xangô. Al recibir la olla, Xangô se retiraba, como si fuera a comer el alimento en secreto, fuera de la mirada de Iansã. Cierto día, Iansã (instigada o no por Oxum, dependiendo de la narración) vio lo que tenía en la olla. Xangô preguntó si Oiá había visto lo que él comía, a lo que ella contestó positivamente. Xangô entonces la llamó para comer (jé, en yoruba) el acará, dividiendo la pelota de fuego con Iansã (IPHAN, 2007; Torres, 2007).

La estrecha relación de las baianas de acarajé con Iansã, orixá guerrera, que carga la espada y que hace justicia, explica por qué ellas salieron a luchar contra la FIFA. Un pequeño resumen de esa disputa será narrado en la siguiente sección. Mientras tanto importa dejar claro que las baianas de acarajé, por su relación con el candomblé, ocupan el espacio público de otra forma: de acuerdo con la explicación de Segato (2005), el público en el candomblé es siempre traducido a los lenguajes del doméstico. Las baianas de acarajé, por lo tanto, domestican al público, entran en ese espacio como si fuera doméstico. Así, son mujeres que no se encuadran en los espacios en los que el género colonial les pretende asignar, $y$ transitan en los espacios femeninos y masculinos/masculinizados (como la calle). Esa es una estrategia fundamental del candomblé para esconderse y sobrevivir.

Acreciento un aprendizaje que considero importante relatar: tuve dudas respecto a si considerar la narrativa del mito como mecanismo de comprensión del caso. No porque no lo viera como conocimiento válido y posible de ser puesto en diálogo con el conocimiento racional/moderno/científico, sino porque temía extender para el "mundo extracomunitario" las llaves de interpretación del conocimiento producido en las comunidades y para las relaciones comunitarias.

Así, percibí lo que parecía obvio: las baianas de acarajé transitan por esa frontera, a pesar de la "división” tradicional/moderno, comunitario/extracomunitario. De acuerdo con Segato (2005), esa es precisamente una estrategia central del mundo negro al generar una religión en el nuevo mundo: hablar del público con categorías del doméstico, o sea, dialogar con el "extracomunitario" con el código "comunitario".

Por ello, entiendo que, porque ellas estaban en lo que pensé era el mundo externo y habiendo sido interlocutoras de la FIFA e interpelantes del Estado, ellas mismas tornaron posible que el conocimiento narrado en el mito hable también sobre esa relación. Tal vez ese también sea un ejemplo de lo que teóricas feministas acordaron llamar "epistemología perspectivista". Es desde la mirada de la baiana, que conlleva el conocimiento mitológico, que se puede emprender la comprensión de la relación que se estableció entre ellas, la FIFA y el Estado.

\section{El conflicto en contra la FIFA, las empresas y el Estado}

Tras la aceptación y elección de Brasil en el 2008 como país anfitrión de la Copa Mundial de la FIFA en el 2014 se crearon una serie de instrumentos para asegurar la más perfecta realización del megaevento en el país. Una de estas medidas fue la aprobación en el 2012 del PL 12663 del 2012, conocida como la Ley General de la Copa. Entre las medidas que dispone la ley estaba incluida la creación de zonas de exclusión alrededor de los estadios, y la prohibición de la venta ambulante dentro de los estadios y zonas de exclusión.

Esa prohibición afecta directamente el trabajo de al menos 400 mujeres que comercializan productos típicos de la cocina baiana, entre ellas las que 
comercializan en los estadios durante los campeonatos de fútbol realizados en la Arena Fonte Nova, elegido como uno de los estadios sede del Mundial. Eso porque la FIFA necesitaba asegurar el beneficio de los patrocinadores del evento, por lo que solo los productos de McDonald's, Budweiser, entre otras empresas del sector de la alimentación, se podrían vender en estos lugares.

Inicialmente, las baianas no creían que serían retiradas del estadio y de las calles. El apoyo de la población de Salvador, y el reconocimiento de la Unesco eran garantías de que el trabajo, aunque informal, era digno y merecía protección. Sin embargo, la FIFA solo autorizaría la permanencia de las baianas si lograban pasar por un proceso burocrático y ganaran la licitación (FIFA, 2012). Tendrían que trabajar para la FIFA, de acuerdo con sus patrones de comercialización, y no de forma independiente, como siempre lo han hecho.

Así, organizadas desde hace años en la ABAM, las baianas emprendieron un proceso de resistencia a la prohibición de sus actividades de producción, luchando por garantizar la protección de los derechos culturales, el derecho al desarrollo y el derecho al trabajo. A priori, la Asociación intento establecer diálogos y negociaciones en las vías institucionales, solicitando reuniones y audiencias con el alcalde de Salvador, el gobernador de Bahía, con el ministro de Deportes y accionó a los fiscales para adjudicar una demanda contra la FIFA. Sin respuestas concretas y con la proximidad de la Copa de las Confederaciones, considerado el termómetro para el Mundial, las baianas realizaron la acción directa en busca de apoyo popular. Meses más tarde, el Instituto del Patrimonio Histórico y Artístico (IPHAN) Estadual también reconoció el oficio de las baianas de acarajé como patrimonio inmaterial de Bahía.

A pesar de ese reconocimiento, que no resultó en ninguna garantía concreta del derecho al trabajo, ellas organizaron, desde octubre del 2012, la recogida de firmas a través de una petición en línea con el apoyo de la oNG Change.org. Después de ocho meses de campaña, realizan una acción de protesta y entregan el documento con más de 17000 firmas de personas de todo el país a las autoridades gubernamentales federales, estatales y locales que estaban en la ciudad el día de la inauguración de la Arena Fonte Nova en abril del 2013. Desde entonces, la FIFA vuelve atrás y acepta la presencia de las baianas en el estadio.

Sin embargo, los directivos de la Arena Fonte Nova no querían su presencia. Al final, durante el
Mundial, solo cuatro baianas pudieron trabajar en el estadio, quedando en un quiosco poco visible, no hubo publicidad de la venta de los acarajés y tuvieron que restringirse a la forma de producción de acarajé impuesta por la concesionaria de la Arena. Con el argumento de que era necesario cumplir con las normas de seguridad e higiene, las baianas fueron obligadas a adaptar sus métodos de producción (quedó prohibido del uso de gas y ollas propios), y adaptarlo a la electricidad. Por otra parte, tenían que ponerse de acuerdo sobre el precio de acarajés con la FIFA, además de quedar prohibida la venta en las gradas del estadio.

\section{Las experiencias de las baianas en los tiempos de megaeventos}

En seguida, presento algunas conclusiones y reflexiones resultado de la observación en campo y de los intercambios en las charlas y entrevistas. Hice incursiones etnográficas y entrevistas con baianas de acarajé que trabajaban en las calles próximas o dentro de lo que sería las zonas de exclusión de la Fifa. Todos los nombres utilizados adelante son ficticios para mantener el anonimato de las participantes.

Todas las baianas entrevistadas afirmaron que sostenían sus familias con la renta de la venta de los acarajés. La mayor, doña Joana, trabajaba hace tantas décadas como baiana de acarajé que no se acordaba cuándo empezó. La bisabuela, doña Joana, cuidó de todos los hijos con la venta de esa comida. Las demás trabajaban hace mucho tiempo en el oficio, entre diez y veinticinco años. La baiana Vera, que "no se sienta" siempre en el tabuleiro porque está activa en la ABAM, pone otras baianas de varias edades en su lugar: la mayor que trabaja en su punto tiene 76 años y la más joven, 35 años. Pero, como me relató esa baiana, la más joven es baiana de acarajé desde los nueve años de edad, pues "la abuela de ella fue baiana de acarajé, la madre de ella fue baiana de acarajé y ella es baiana de acarajé, empezó a los 9 años. Y todas ellas se sostienen con ese trabajo" (Vera, 18 de septiembre del 2014, comunicación personal).

Las baianas que trabajaron, con o sin autorización, tuvieron experiencias distintas en cuanto al cumplimiento de sus expectativas más inmediatas: obtener renta durante el Mundial. La baiana Vera y la baiana Lúcia, que trabajaron dentro de la Arena Fonte Nova, tuvieron impresiones diferentes: Vera obtuvo renta suficiente para dividir con las demás baianas que fueron sus auxiliares y cubrir los costos de producción, pero no obtuvo beneficios. Sin 
embargo, el objetivo de Vera al sentarse en el tabuleiro es librarse del estrés de la vida diaria, sacar de sí toda la energía negativa, además de sentirse satisfecha en ofrecer el acarajé a los visitantes. Conforme me relató, en las fiestas de São João, por ejemplo, ella no se sienta en el tabuleiro, porque hay otras baianas que lo necesitan más, y ella entiende que no hay necesidad de crear más una concurrencia. En carnavales, otra gran fiesta en Salvador, ella insiste en sentarse todos los días, porque viene mucha gente y ella se siente muy alegre en ofrecerles el acarajé. Así, considerando que no tuvo perjuicios y pudo contribuir con la renta de las otras baianas, quedó satisfecha con lo que recibió.

Ya la baiana Lúcia había trabajado dos partidos en el estadio, pero como estaba rindiendo, resolvió irse al punto que tiene fuera, donde lucró, conforme me relató, hasta cuatro veces más por partido que dentro de la Arena. El punto de Lúcia, se ubica hace años frente al Museo Náutico, en Farol da Barra, donde fue organizada la FIFA Fanfest. Ella no tenía autorización para quedarse allá, pero resolvió enfrentar el poder público y la FIFA, para conseguir trabajar. Ella me relató que denunció en las redes sociales, radios, emisoras de televisión, reclamó mucho, porque "no hallaba justo que nos sacaran de acá, tres baianas, patrimonio, para poner tres baianas de fuera. Y si yo me quedo, las otras dos también se quedan, porque si yo almuerzo, ellas también ponen comida en casa al medio día" (Lúcia, 19 de septiembre del 2014, comunicación personal) Así, la municipalidad acabó por aceptar que ella y las otras dos baianas que trabajan en esa plaza hace años pudieran quedarse.

El impacto de la retirada de las baianas de sus puntos se extiende más allá de la vulnerabilización económica de esas mujeres y de sus familias. Como me relató Vera, eso afecta un hábito que los habitantes de Salvador tienen hace décadas y que siguió a lo largo de los años: cuando no se tenía teléfonos móviles, las personas necesitaban marcar puntos para encontrarse, y los tabuleiros de las baianas eran punto de referencia para los encuentros.

Hasta el día de hoy, cuando se pretende encontrar alguien, se indica el punto de Cira o Dinha (puntos de baianas más conocidas en Salvador). Dentro de la Arena Fonte Nova, las baianas también tenían una función referencial en el espacio, pues servían para que los aficionados pudieran encontrar en medio de la multitud. De acuerdo con la baiana, incluso dentro de la Fanfest, las personas marcaban de encontrarse frente a su punto, y aprovechaban y comían el acarajé.
Se trata, pues, de un elemento de identificación importante, porque la gente tiene condiciones no solo de ubicarse en la ciudad, pero también, en el caso de los habitantes, de afirmar su baianidade, y en el caso del turista, de apropiarse de esa baianidade ${ }^{1}$ y sentir que conoció la ciudad en sus aspectos más cotidianos.

Esa observación coincide con lo que afirman las investigadoras Lígia Amparo da Silva Santos (2008) y Taís Sant'Anna Machado (2013). Según Machado, al comer, el comensal se torna parte del grupo y, en consecuencia, de un ideario: "Comer es pertenecer" (Machado, 2013, p. 243). De acuerdo con Santos, al consumir el acarajé, tanto los soteropolitanos (habitantes de Salvador) como los turistas están consumiendo una "Bahia longiqua". Eso significa recuperar y reconstruir la historia de la ciudad, y contribuir para el descubrimiento y reafirmación de la memoria colectiva de Bahia.

Fuera del estadio, la baiana Rosa trabaja en el oficio hace 20 años y tiene a su hijo como ayudante. Ella relató que "teimou" (fue terca) y consiguió trabajar durante el Mundial, en su punto en el Largo de los Salesianos, sin autorización de la FIFA o de la municipalidad. Sin embargo, a causa de las calles cerradas y vigiladas, el movimiento cayó un $80 \%$ y tuvo muy poco retorno financiero. Así, aumentó el precio del acarajé para compensar la falta de demanda y el aumento del precio de la materia prima. Rosa me contó que el "rapa" (policía o funcionario de la secretaria de orden pública) estaba vigilando quién tenía autorización y atribuyó al "miedo del rapa de meterse con las baianas de acarajé" el hecho de que no le cuestionaron si tenía autorización.

Es decir, la permanencia de las baianas en las calles de Salvador por siglos, aunque con el enorme control sobre sus cuerpos por medio de varios discursos, se debía, entre otras cosas, a que el "rapa" tenía miedo, o respeto, a las baianas de acarajé, pues sabían de la relación religiosa que ellas tienen con los terreiros y "casas de candomblé". Así, el miedo de "recibir un hechizo" o el respeto a esas mujeres que están cumpliendo con sus obligaciones de santo (frecuentemente el "rapa" mismo hace parte de un terrero e integra

$1 \quad$ En ese trabajo utilizo el término bainidade usado por los medios y estudiosos del tema para designar la esencia de lo que es ser baiano. Según Milton Moura, se trata de un "texto identitário" compuesto por signos como familiaridad/intimidad, sensualidad y religiosidad, y que remite a un pueblo vinculado a un pasado rememorado y de fuerte ligación con el continente africano (como se citó por Machado, 2013, p. 242). 
la red de solidaridad de esas mujeres) eran motivaciones para que esos agentes públicos se hicieran los de la vista gorda con supuestas irregularidades y no interfirieran en el trabajo de ellas.

De acuerdo con Gerlaine Torres (2007), a lo largo de su historia, las baianas son discriminadas por las élites y por el poder público, principalmente en los siglos XIX y Xx. Los saberes médicos, en la tentativa de manipular las patologías del femenino, contribuyeron para la reorganización del espacio urbano y del espacio público. Torres explica que una forma de control sobre las mujeres negras que circulaban por las calles se dio mediante la vigilancia sanitaria. Muy fuertemente, el discurso de la higiene era usado para uniformizar el vestuario, los utensilios y aparatos de trabajo, la producción, la venta y, no menos importante, los cuerpos de las callejeras. Antiguamente, "el problema era la manipulación de los carbones en los berberechos, ya que por ser una substancia sucia, producía un ennegrecimiento indeseable de las manos" (Torres, 2007, p. 159; cursivas añadidas).

A lo largo de los años, el control recayó sobre los alimentos del tabuleiro (se prohibió la venta de entrañas de animales y otras carnes, después frutas y verduras) y sobre el tabuleiro mismo, que pasó a ser cubierto con una tapa, contra los rayos ultravioletas. De acuerdo con la autora:

El deseo de uniformización del alimento es el deseo de eliminación de la alteridad y de su visión de mundo, ambos encarados como atributos demoníacos o resquicios atávicos peligrosamente próximos de pulsiones agresivas e transgresoras. Esas fórmulas biologizantes, que parecen salidas del siglo xix o de la primera mitad del siglo $\mathrm{xx}$, se revistieron con nueva ropaje y terminaron por anclarse en el discurso de la higiene. Por ello, la higiene, en ese caso de las comidas de tabuleiro, aún es una cuestión de domesticación y de control (Torres, 2007, p. 160).

A pesar de eso, las baianas que pudieron trabajar, a diferencia de las que no, consideraron que las exigencias que les hicieron no eran demasiadas, no afectaron su forma de producir el acarajé y se esforzaron por cumplirlas. Incluso la freidora eléctrica fue bien recibida, porque es más liviana y más fácil de proteger del viento. Como me relató la baiana Lúcia: "todos los cursos de higiene, de administración, de todo, atención al cliente, idiomas, todo yo salgo adelante y pongo mis niñas para hacer también. De esa forma, yo busqué me adecuarme a lo que vigilancia sanitaria quería, yo voy siempre adelante" (Lúcia, 19 de septiembre del 2014, comunicación personal).

Esa estrategia de adaptarse a las exigencias de la FIFA y de los poderes públicos, cumplir con ellas y seguir adelante es considerada por ellas como una forma de "lucha". Es "salir adelante", "no dejarse ser pasada para detrás”, "poner la frente adelante”, características muy presentes en los mitos sobre Oiá. Estas fueron expresiones utilizadas en las charlas y entrevistas para hablar tanto de la adaptación de las baianas a los cambios y dinámicas que los organizadores del megaevento impusieron, como de otras situaciones en las que el oficio es puesto en jaque.

\section{Amefricanidade dentro y fuera de campo}

En ese sentido, comprendo que en la lucha de las baianas todavía hay dos aspectos que son distintivos de su proceso de resistencia: hay un sistema simbólico, que constituye las identidades afrobrasileras, construido colectivamente y a lo largo de los siglos, está en juego y es el porqué ellas luchan para preservarlo. Además de eso, ese proceso no se inició en la pelea con la FIFA ni se cierra con el fin de los megaeventos; es parte de la historia de las mujeres negras en Brasil. Cuando se aprende el oficio, se recibe una herencia que dice respeto no solo al sistema alimentario en el que acarajé está inserido, sino que también a la sabiduría relativa a los conflictos de la vida cotidiana.

Para Torres, "la insistencia en la preservación de un sistema simbólico religioso afrobrasilero como respaldo de su actividad durante esa trayectoria se asemeja al que Michel Foucault [...] nombra de 'resistencia difusa"” (Torres, 2007, p. 249). Como se dijo anteriormente, hay diversos ejemplos de los controles de las instituciones disciplinadoras sobre las baianas:

Vigilancia policial, tentativas de formalización del comercio, medicalización del universo de trabajo por medio del sanitarismo [y en tiempos más recientes], las exigencias de eficiencia pautadas en un modelo fabril y las tentativas de escolarización del aprendizaje tradicional a partir de los cursos de gastronomía e higiene, técnicas de capacitación disciplinadoras en función de la industria del turismo soteropolitana (Torres, 2007, p. 250).

Así, la autora explica que en el contexto más amplio de una cultura de trabajo afrobrasilera, el nuevo tipo de subordinación instaurado por la disciplina 
del modelo fabril fue históricamente rechazado por las baianas de acarajé, muy probablemente como resultado de la devastadora experiencia del régimen esclavista. Según Reis, esa cultura de trabajo, que fue delineada aún en el período colonial, está basada en la valorización de la autonomía (Torres, 2007, p. 252).

En razón de eso, afirma Torres que las vendedoras resistieron de una manera propia, con respuestas culturales a las situaciones adversas inmediatas que les eran puestas en el camino: "Escapaban de la cobranza de impuestos, ignorando decretos, aliándose a los que necesitaban de su renta, por medio del 'gano', constituyendo grandes familias, buscando nuevos puntos, buscando prestigio y construyendo una red de relaciones indispensable para la sociedad" (Torres, 2007, pp. 252-253). Ese saber mercantil expresaba una herencia cultural de pueblos africanos.

Considero, pues, que esas experiencias de lucha, sea por el embate directo, por la testarudez, por la negociación, por la adaptación, son parte del repertorio de estrategias que los negros esclavizados durante la colonia y sus descendientes accionaron para realizar su "proyecto de pueblo", o sea, para definirse y garantizar la continuidad de los pueblos en la historia (Segato, 2012). A ese repertorio Lélia González (1988) nombró amefricanidade.

La expresión amefricanidade surge en el contexto de diálogo de la autora con los autores estadounidenses que estaban reflexionando sobre las relaciones raciales que se establecieron y se perpetuaban en los EE.UU. Reflexionando sobre una perspectiva considerada decolonial (Cardoso, 2012), Lélia Gonzalez propuso cuestionar el lugar que ocupaban en la geopolítica de las universidades los negros esclavizados en las tierras de Suramérica y el Caribe, así como sus descendientes. Cuestionaba por qué los autores de los EE.UU se "olvidaban" que había negros en otros espacios también colonizados. Con ello, afirmaba que existía una posición imperial de esos autores que consideraban solo a EE.uU como América. Propuso, así, el término amefricanidade como una expresión capaz de designar a todos nosotros, todos los pueblos colonizados en América.

Así, Gonzalez define amefricanidade en los siguientes términos:

Las implicaciones políticas y culturales de la categoría amefricanidade son, de hecho, democráticas: exactamente porque el propio término nos permite ultrapasar las limitaciones de carácter territorial, lingüístico e ideológico, lo que abre nuevas perspectivas para un entendimiento más profundo de esa parte del mundo dónde esta se manifiesta: la América y como un todo (Sur, Central, Norte e Insular). Además de su carácter puramente geográfico, la categoría de Amefricanidade incorpora todo un proceso histórico de intensa dinámica cultural (adaptación, resistencia, reinterpretación y creación de nuevas formas) que es afrocentrada, eso es, referenciada en modelos como: la Jamaica y el akan, su modelo dominante; el Brasil y sus modelos yorubá, banto y ewe-fon (González, 1988, p. 76, traducción propia). <Fin de cita $>$

Es decir, la amefricanidade, para Gonzalez, refleja la experiencia histórica de la diáspora y la herencia africana que reavivaron las fuerzas de la resistencia y la creatividad en la lucha contra la esclavización, el exterminio, la explotación, la opresión y la humillación que la colonialidad del poder creó (González, 1988, p. 78). Hay un énfasis de González en recordar la lucha y el sacrificio de los antepasados que abrieron caminos y perspectivas para el ser afroamericano de hoy. Según la autora, su insistencia se debe al hecho de querer destacar el carácter histórico de la categoría que floreció y se estructuró en el transcurrir de los siglos que enmarcan la presencia de amefricanos en el continente y antes en la llamada América precolombina.

En esa perspectiva, González explica que la amefricanidade ya se manifestaba en el periodo colonial, "en las revueltas, en la elaboración de estrategias de resistencia cultural, en el desenvolvimiento de formas alternativas de organización social libre" (González, 1988, p. 79) que, hoy día, se materializa en los quilombos, por ejemplo, y en el oficio de baiana de acarajé. Conforme dije, considero que el oficio que es pasado de madre para hija o entre mujeres de la familia o próximas a ella es ejemplo de amefricanidade; es diferencia decolonizada y estrategia de resistencia, que se constituyen.

Pero el oficio de baiana de acarajé no se constituye solo de saber práctico relacionado con el alimento y la herencia de resistencia; hay también un secreto, propio de los oficios, compartido entre las baianas promedio, de códigos y conocimientos que no pueden, o no deben, ser totalmente traducidos al lenguaje del colonizador. A partir de eso, debo sumar a la amefricanidade de Gonzalez el conocimiento y el código propios de los pueblos originarios y en diáspora de América.

Así, comprendo la amefricanidade como las estrategias de negociación, adaptación, lucha y 
supervivencia desarrolladas desde las experiencias, pensamientos y reflexiones en un proceso de intersección entre el conocimiento propio y el conocimiento del otro, entre el código del otro y el código de esos resistentes. La autora habla de "pretuguês", portugués negro creado en Brasil desde las expresiones compartidas por los negros esclavizados. Pero no habla, por ejemplo, del corpus mitológico como discurso de verdad y conocimiento sobre la realidad.

Eso pues, como dije, y en las explicaciones del porqué las baianas habían decidido luchar para garantizar que pudieran trabajar durante el Mundial, en la investigación, con frecuencia, aparecen elementos del código "ordinario" y del código "comunitario": "no es justo", "no es correcto", "es falta de respeto", "la FIFA no es mejor que las baianas", "el McDonald's no puede hacer acarajé".

Entiendo aquí por "código ordinario" los signos construidos, utilizados y constituyentes de los poderes coloniales modernos y por "código comunitario', los signos construidos, utilizados y constituyentes de los pueblos colonizados. Tal división no es excluyente, de forma que hay intercambios entre esos códigos en las relaciones entre los diversos sujetos; pero, en concordancia con el eje argumental de la colonialidad del saber (Quijano como se citó en Segato, 2013), comprendo que esos códigos son frecuentemente jerarquizados, de modo que se hegemonizan las formas de interpretación y comprensión de la realidad en torno del pensamiento eurocentrado y, por eso, considero importante distinguirlos.

Sobre ese asunto, es particularmente interesante la siguiente explicación que me fue dada:

¿sabe por qué nosotras no dejamos pasar esa historia de la FIFA? Nosotras estamos acostumbradas, que cuando es fiesta importante, ellos nos quitan, pero después siempre volvemos. Pero sabes, el acarajé es de Iansã, entonces ¿crees que ella se iba quedar tranquila? (Lúcia, 19 de septiembre del 2014, comunicación personal).

Según los mitos yorubanos, Iansã es un orixá guerrero, que se posiciona frente a Xangô en las batallas, lo auxilia y abre caminos para ese orixá en las guerras. De esa forma, la orixá estaría guiando a las baianas para ir a la lucha, impulsándolas a rebelarse, a afrontar un poder más fuerte.

Eso ayuda a comprender también por qué era importante para las baianas servir de "ejemplo" para otros grupos y colectivos que también estuvieron interpelando la FIFA por la violación de sus derechos. En entrevista a un periódico, el Correio Nagô ${ }^{2}$, la presidenta de la авам, Rita Santos, afirmó que "[...] lo más importante no es estar allá vendiendo, es estar en la calle y mostrar que nosotras lo conseguimos. Porque nosotras abrimos puertas para que en otros estados pudieran estar ahora en el Mundial, las tapioqueiras de Recife y el frijol tropeiro de Minas Gerais"3.

En otras palabras, la amefricanidade reúne no solo las experiencias prácticas de negociación y resistencia en la lucha cotidiana de las relaciones coloniales, sino también el conocimiento mitológico que refleja las expectativas, las frustraciones, los deseos, las necesidades y las proposiciones de verdad que los pueblos colonizados han compartido en la continuación de esa lucha por un proyecto de ser.

\section{Algunos aspectos más de otra racionalidad}

Volviendo a los relatos, las baianas que no trabajaron durante el Mundial tuvieron entre sí experiencias con semejanzas y diferencias. Todas ellas no obtuvieron renta suficiente como para cubrir los costos de la producción. Por otro lado, lidiaron con el problema de la prohibición de la venta del acarajé próximo a las zonas de exclusión de maneras distintas. Algunas que no pudieron trabajar en sus puntos relataron que cambiaron el punto de lugar, para otros locales o en calles próximas a las zonas de exclusión. Otras decidieron no vender, y relataron que tuvieron perjuicios. La baiana Constancia, por ejemplo, además del perjuicio, perdió su ayudante, que tuvo que buscar otro trabajo. La baiana Zulma, por su parte, dijo que prefirió "vender encomiendas de abará ${ }^{4 ”}$ (Zulma, el 20 de septiembre del 2014, comunicación personal).

Un aspecto importante del oficio de baiana de acarajé es el hecho de ser un trabajo cuyo retorno financiero varía mucho, dependiendo de diversos factores: flujo turístico, cambios meteorológicos, variación en el precio de la materia prima, realización de fiestas conmemorativas, divulgación por los

2 "A Baiana que desafiou a FIFA - Rita Santos". Recuperado de https://www.youtube.com/watch?v=8kl Dx7aIqTg\&feature $=$ share .

3 Las tapioqueiras e tropeiros son también cocineros y vendedores callejeros de comidas típicas de los estados del Noreste del país y de Minas Gerais

4 Abará: comida típica. 
medios. En temporada de vacaciones, el número de turistas en Salvador tiende a aumentar, lo que hace subir las ventas; en meses de más lluvia es más difícil mantenerse en las calles; en las fechas conmemorativas, como las fiestas religiosas, se incrementa el consumo del acarajé, junto con el valor de las materias primas; la propagación de informaciones negativas sobre las baianas y el acarajé puede resultar en la reducción del consumo, como en el comienzo de la década del 2000, cuando se divulgó la información de que había coliformes fecales en los acarajés.

En razón de eso, las baianas relatan que están acostumbradas a esa inestabilidad del oficio y crean diferentes formas de equilibrar la renta a partir de lo que ganan a lo largo del año. Los métodos y técnicas para hacer ese equilibrio dependen de cada baiana, según las experiencias propias de producción, venta, relación con los consumidores, con la red de familiares que las apoya y en la relación que establecen entre el oficio y la religiosidad. Las relaciones que se establecen en el 'negocio' de las baianas de acarajé se presentaron para mí como diferentes de las relaciones capitalistas, pautadas en la plusvalía, en la austeridad, en la acumulación, en la explotación de la gente y de su entorno natural, y en la racionalidad instrumental del homo ceconomicus. Resalto, pues, que el conocimiento y las prácticas económicas de las baianas de acarajé se conocen poco y probablemente no se traducen al patrón de construcción del conocimiento de la disciplina de la economía.

De acuerdo con Torres, es lo cotidiano lo que pauta la adaptación de las baianas. Frente a cualquier posibilidad de quiebra en un corto plazo, una opción a la que se recurre es parar, sin que se tenga grandes perjuicios, ya que la inversión de recursos es baja (no fue ese el caso, pues invirtieron en gran cantidad de materia prima, pensando que iban a vender durante el Mundial); otras opciones también están disponibles, como cambiar el punto de venta o esperar por tiempos mejores (Torres, 2007).

Por eso, para la autora, se vuelve equivocado interpretar a las baianas fuera del contexto de su propio saber. Según Torres:

Si logramos verlas mínimamente dentro de ese contexto, una actitud que parece poco hábil para los negocios - a los ojos de quienes generalmente se olvidan del peso histórico de la actividad- se vuelve otra visión del comercio, más de acuerdo con un cotidiano palpable que con una economía racional y sus previsiones de largo plazo (2007, p. 247).
En conformidad con la lógica presentada anteriormente, la baiana Lúcia me relató que ella no tenía noción exacta de lo que producía y recibía por mes, resaltando que intentaron enseñarle, en vano, métodos de contabilidad microempresarial:

Ninguna baiana tiene, específicamente, específico, detallado, cuánto gana mensualmente. Yo tengo mi control por kilos de masa, ya intenté hacer control junto con los cursos, no, que ellos ofrecen, pero no conseguí, de auxiliar de administración y todo lo demás, pero no pudo hacer. Hasta porque baiana puede aumentar o disminuir el tamaño del acarajé para tener un rendimiento más grande en la cantidad de masa, entonces queda difícil, la cantidad real... (Lúcia, entrevista realizada el 19 de septiembre de 2014).

Resalto que, en todos los relatos, en diversas situaciones, durante charlas informales, entrevistas, antes y después del Mundial, las baianas destacaban el deseo de que fueran respetadas. Las expresiones "nosotras queremos respeto", "nuestro trabajo merece respecto", "quiero que me traten con respeto y dignidad", "sin respeto ninguno ni dignidad ninguna... nosotras no sostenemos", aparecieron constantemente, con frecuencia relacionadas con la evaluación sobre ser 'patrimonio', como "nos dieron el título de patrimonio, entonces nos tienen que respetar", "pensamos que cuando fuéramos patrimonio el Estado nos iba abrazar y proteger como si fuéramos hijas, pero aún así no somos respetadas...", "me gustaría que ellos nos respetasen más e hicieran valer el documento del IPHAN, porque baiana es patrimonio inmaterial nacional".

Observé, pues, que la expresión que representa el deseo de las baianas para que puedan seguir realizando el oficio es el respeto. Percibí que el sentimiento de indignación de esas mujeres se dio por la falta de respeto que resultó de las relaciones de poder que se establecieron. En mi interpretación, el respetar aquí significa reconocer la diferencia, atender a las necesidades, permitir la presencia de ellas y no interferir en su oficio.

Resalto también el Taller de Historia de Vida, realizado en el seminario de evaluación en el que participé con ellas después del Mundial. Cerca de treinta baianas participaron del taller, momento enriquecedor y revelador para la investigación. Una de las enseñanzas fue la importancia que ellas dan al oficio como trabajo, que adquirió dos acepciones diferentes y correlacionadas: el trabajo que constituye sus subjetividades y el trabajo que las sostiene y dignifica. Por 
lo que pude entender, ser baiana de acarajé significa ser mujer, igual que a los hombres, porque pueden ser poderosas y autónomas. Eso las vuelve merecedoras de respeto, pues tienen condiciones de sostenerse a sí mismas y a sus hijos, a sus padres y ancestros, y sus comunidades. Como me dijo una de las participantes, "el acarajé ya mató mucho mi hambre y el hambre de mis hijos" (baiana anónima, Taller de Historia de Vida realizado el 18 de septiembre del 2014).

Como se enseñó en el taller de lengua y cultura yorubana del mismo seminario, la expresión de los sentimientos no se da con el corazón, sino con el estómago. Varias expresiones lingüísticas de los sentimientos se constituyen con palabras que derivan de la idea de estómago (inú, en yorubano): "Inúmidú morié" - mi estómago está muy feliz en verte-; "Inubajé" - estoy enojado-. Ofrecer comida, en esa perspectiva, es más que satisfacer una necesidad vital; tiene relación con la a oferta de sentimientos, además de significar compartir o renunciar. Así, ser conocedora de una práctica que resulta en la producción de alimentos es extremadamente importante, porque significa tener poder de distribuir bien-estar, hacer proliferar sentimientos, y renunciar a la usura y el egoísmo.

En las historias de vida, también fue bastante enfatizado el enorme vínculo entre las baianas de acarajé y sus familias. Como dije antes, es el acarajé, para comer o para vender, el que permite la supervivencia de ellas y la de sus hijos. Ese vínculo es establecido también por el hecho de ser un saber pasado entre mujeres, de abuelas a nietas, de madres a hijas, de tías a sobrinas y agregadas, suegras y nueras, vecinas, amigas e incluso padres y cónyuges. En fin, el parentesco es reafirmado o establecido por medio del aprendizaje y enseñanza del oficio.

Además, como dije antes, la resistencia - a las condiciones socioeconómicas y las tentativas tanto de sus maridos como de las élites y del Estado de impedirles trabajar - se aprendió con las madres y abuelas. Según relató una participante:

Mi madre empezó a vender acarajé, quebrando el fríjol en la piedra. Nosotras guardamos la piedra hasta hoy en casa. Mi madre fue una mujer que resistió a mi padre que decía que la mujer de él no trabajaba y mi madre empezó a vender a escondida con la abuela de mi abuela. Entonces yo ya vengo de esa historia de lucha porque yo vine desde mi abuela... (baiana anónima, Taller de Historia de Vida, realizado el 18 de septiembre del 2014)
En todos los grupos del taller de historias de vida, se resaltó el carácter conflictivo de la realización del oficio, siempre inserto en el contexto de luchas colectivas e individuales, lo que revela una característica también muy hablada por ellas, el ser guerrera: "Tengo que hacer como mi madre, Oiá, guerrera, no tener miedo de luchar por mis cosas, para cuidar de mis hijos" (baiana anónima, Taller de Historia de Vida, realizado el 18 de septiembre del 2014).

\section{Sistemas de opresión articulados}

Cuando llegué, antes de la Copa de las Confederaciones, en Salvador de Bahia, la ciudad donde se concentran más baianas de acarajé y donde se desarrolló la lucha de esas mujeres, me encontré con banners turísticos del Gobierno, en donde están las baianas de acarajé que dan la bienvenida a los visitantes de la ciudad. A ese respeto, Gerlaine Torres (2007) nos explica que del resultado de los cambios de lo que hoy se define como universo afrobrasilero, frecuentemente visto como representación nacional de la afrobrasilidad, es una cara étnica específica que cada vez se vuelve más global. Las baianas tienen una relación muy próxima de ese tipo de representación: ellas son parte de eso (Torres, 2007, pp. 16-17). Más adelante, al analizar un cartel de la FIFA, percibo que las baianas integran una unidad, como representación en la nación y de esta.

También las baianas de acarajé fueron representadas como símbolo de baianidade, atractivo turístico o, como ellas mismas dicen, "baianas postales". La figura 1 muestra una imagen del principal sitio electrónico sobre el Mundial de Fútbol del 2014 del país:

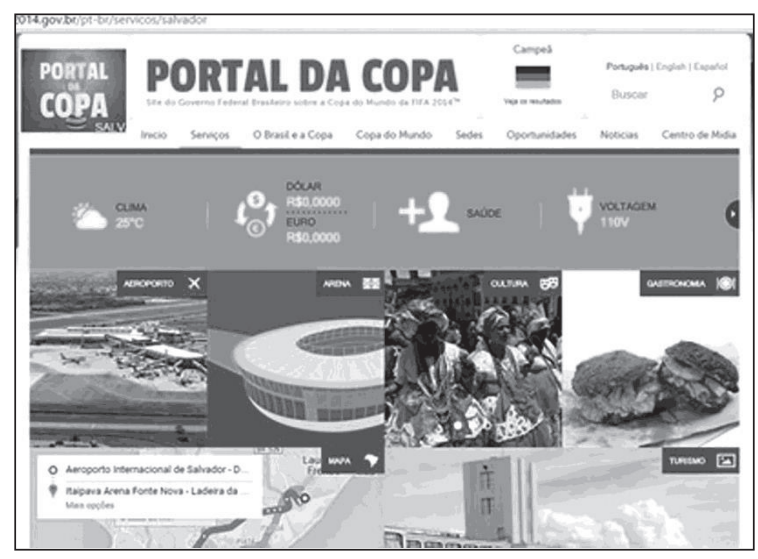

Figura 1. Sitio oficial del Gobierno para el Mundial. Tomado de http://www.portaldacopa.gov.br 
En la figura 1, se puede ver que en el enlace "gastronomía" está el acarajé y en el enlace "cultura" están las baianas de acarajé, al lado del nuevo estadio de fútbol, Arena Fonte Nova, y del aeropuerto ampliado. ¿Qué significa eso? Las baianas de acarajé representan lo tradicional, lo colonial, lo diferente que es la Bahia. Al mismo tiempo, lo tradicional convive con lo moderno, ya que las baianas circulan por una ciudad que está siendo modernizada, recibiendo diversas inversiones para ser transformada en una "ciudad global", completa, en el sentido de que es capaz de reunir belleza y atractivos turísticos, eficiencia y competencia necesarios para atraer inversores y entrar en la red de flujos globales de capital.

Así, lo que quiero mostrar con este ejemplo del material turístico es que lo tradicional, lo diferente y exótico pulsa libremente en las calles modernas y modernizadas de Salvador, una ciudad en donde las mujeres tienen autonomía económica, circulan libremente, alegres y satisfechas, y ocupan la ciudad. Eso en parte es verdad. Sin embargo, subyacente a lo que se ve es la tentativa de ocultar la opresión y vulnerabilización a la que se ha sometido a esas mujeres: se muestra la cara de la baiana, bonita, con su trabajo; se ocultan sus sufrimientos y angustias por no saber del día de mañana, ya que la FIFA y los poderes públicos tienen el poder de decidir hasta dónde va esa autonomía y libertad.

La figura 2 es un material producido para el Mundial del 2014 que me llamó la atención. Percibo el cartel oficial de la FIFA como la materialización icónica de las relaciones de poder entre el frente estatal-empresarial y las baianas de acarajé. El cartel presenta el territorio brasilero constituido por diversos elementos. En todo, en el mapa, pero principalmente en el norte, podemos ver elementos relacionados a la naturaleza, representantes de la fauna y de la flora brasilera, como el colibrí, el tucán, el tití león dorado, el lagarto, los árboles de coco, guaraná, plátanos, café, etc. También hay símbolos regionales, como la calabaza de mate, el buey de las fiestas Bumba-Meu-Boi, el sombrero de cangaceiro; elementos musicales, como el berimbau y el pandeiro, o monumentos arquitectónicos que conforman los paisajes de ciudades, como Corcovado, Cristo Redentor, el paseo marítimo de Copacabana, los Lençóis Maranhenses. Los representantes de las expresiones culturales brasileñas también forman parte de la figura, como la bailarina de frevo, los capoeiristas y la baiana de acarajé. Los límites del mapa están delineados por las piernas de dos jugadores de fútbol que están compitiendo por

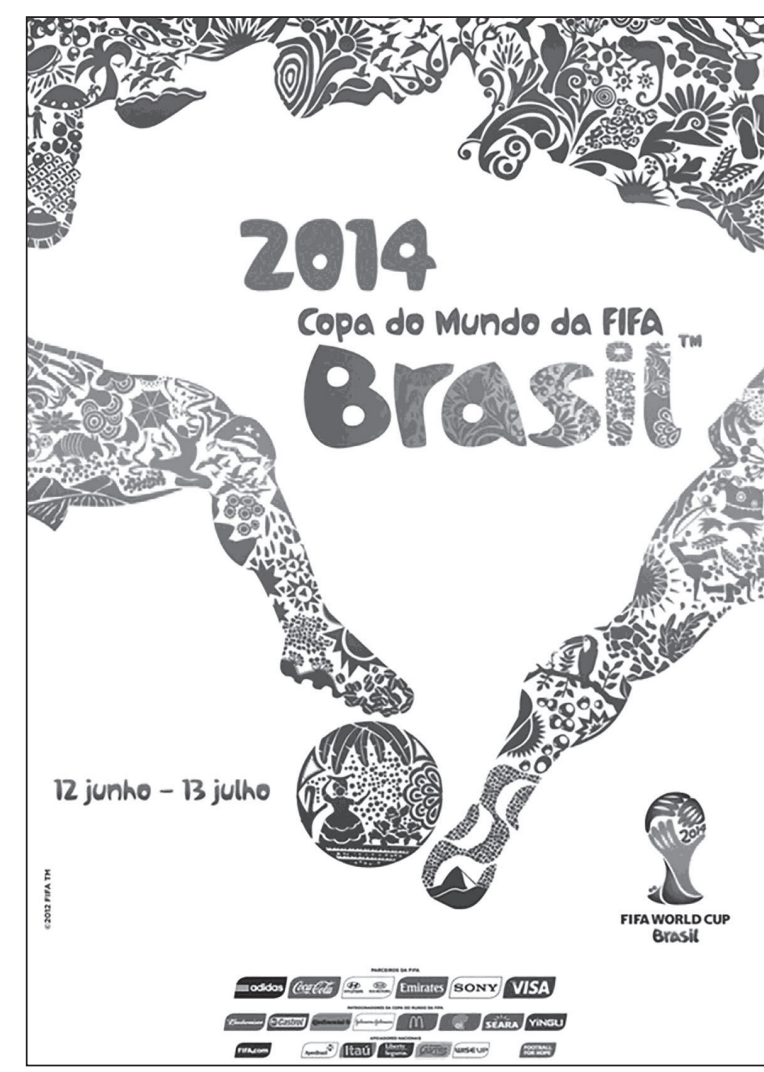

Figura 2. Cartel oficial de la Copa del Mundo de la FIFA 2014. Tomada del Portal Oficial da Copa-Governo Brasileiro.

una pelota. En el centro de la bola está una baiana de acarajé con una tabla en la cabeza. Todos estos elementos constituyen, en su conjunto, una unidad, la nación brasileña. De acuerdo con Crama, compañía que creó la pieza, el concepto "un país entero al servicio del fútbol -Brasil- y el fútbol, una identidad compartida" inspiró la creación de este cartel.

Podemos hacer al menos dos lecturas de la baiana en el centro de la bola. En una primera lectura, se entiende que la baiana, mujer negra, signo subordinado en la relación colonial, está entre dos hombres y literalmente es jugada de un lado a otro. Es metafóricamente el cuerpo-territorio (parte del territorio brasileño, en la composición mapa) con el que los hombres de la élite mafiosa del frente estatal-empresarial juegan todo el tiempo.

Esta lectura se basa en las articulaciones de categorías utilizadas por Segato (2013a) ySegato (2015). En el texto, la autora tiene como objetivo presentar una visión general de los crímenes contra las mujeres en Ciudad Juárez, articulando el cuerpo como territorio de disputa política y el locus de enunciación de 
los mensajes sobre el poder, el control, la soberanía, la lealtad, entre otros.

Según la autora, en la recurrencia de delitos contra la mujer desde hace más de 11 años se entiende que los autores de estos crímenes tienen los recursos de todo tipo, incluso inculcados en las esferas federales del poder, al igual que las mafias. La impunidad de estos crímenes es el resultado de la interferencia que las mafias tienen en la administración. Y funcionan, pues, como un segundo estado.

La articulación de la posesión de los recursos económicos con la posesión del cuerpo femenino y feminizado, se explica porque "la desigualdad económica [...] simbólicamente apoya el sentido de propiedad y dominio que subyace en las relaciones de género [...]" (Segato, 2013a, p. 16), lo que configura una desigualdad. Esta desigualdad interna se puede extender fácilmente a las relaciones entre lo local y lo internacional, como en este caso. La relación que se establece entre las baianas de acarajé y la FIFA nos dice, por lo tanto, de la hegemonía de las mafias del capital internacional sobre el nacional.

Así, según Segato (2015), las situaciones dispersas de violencia contra las mujeres, aunque más frecuentes, son epifenómenos de circunstancias históricas de las relaciones sociales con la naturaleza. Ella considera, por lo tanto, que hay una extraña afinidad entre la explotación económica característica de nuestro tiempo (con nuestro abuso del cosmos natural) y el actuar de una élite que predica y practica un proyecto económico, cuya tendencia es la concentración extrema y que tiene como horizonte el mercado mundial. Los antagonistas de este mercado global terminan siendo los mercados locales. En la figura, percibo haber también esa afinidad entre la actuación de la FIFA, que puso su mirada de rapiña sobre el mundo y la exploración de cuerpo-territorio representado en el mapa.

Por lo tanto, según esta primera lectura a través del mapa, las élites muestran simbólicamente que detentan el poder económico y político, y pueden movilizar, incluso discursivamente, los recursos económicos y jurídicos para legitimar la violencia y la exclusión que están produciendo. La FIFA se valió de varios recursos para justificar la excepción, que se profundiza y se convierte en permanente, lo que Segato (2015) ha construido conceptualmente como "conquistualidad del poder", una nueva fase de la conquista de los territorios, rapiña de todos, sin límites legales.

Por otro lado, en una segunda lectura, se percibe que, una vez en la pelota, las baianas se están moviendo, en acción, y van donde quieren, como la pelota. Los jugadores parecen tener el control de la dirección en la que la pelota va, pero a menudo son sorprendidos por su cambio de dirección. De esa manera actuaron las baianas en la pelea con la FIFA: las mujeres negras en movimiento, sujetos políticamente activos que, como vimos, utilizan varias estrategias de vizibilización de su lucha y resistencia al control estatal-empresarial, no aceptaron el rumbo que la FIFA y el Estado querían darles la exclusión de la Copa del Mundo y la expulsión del espacio público.

Me di cuenta, también, en el campo, de los aspectos del oficio de baiana de acarajé que me permitieron elaborar un nuevo punto de vista económico. La diferencia de las baianas de acarajé no se manifiesta solo en sus ropas, la simpatía y tantos elementos que los estudiosos han tratado de caracterizar y el IPHAN se encargó de compilar y delimitar. Esa diferencia indica otra lógica económica, una entre muchas posibilidades de actuación en las brechas del sistema capitalista mundial, una brecha decolonial.

¿Qué fue la insistencia de la negación de la participación de las baianas de acarajé en el Mundial sino racismo denegado, moderno, que creó mecanismos para legalizar la explotación del capitalismo en las relaciones capital-trabajo y, al mismo tiempo, operar extralegalmente a través de los sistemas de autoridad y en las instituciones democratizadas para subordinar genérica y racialmente a los brasileros y las baianas? Me parece que, para profundizar en el racismo del frente estatal-empresarial, sería necesario contextualizar e historizar la perspectiva del sistema mundo colonial moderno, porque ahora las élites internacionales y transnacionales interpelan el signo de "otredad" desde múltiples espacios-tiempos, en el espacio globalizado, discontinuo y heterogéneo.

Como sujetos "inferiores" que son en relación con el patrón capitalista moderno y eurocentrado, las baianas representan el signo del retraso, de lo tradicional, de lo colonial, de lo premoderno, del subdesarrollo que, por resistencia e insistencia, persisten en nuestro paisaje humano, como grano en los ojos o piedra en el zapato, o, como ellas mismas nos enseñan, indigestas (recuerden que a menudo los sentimientos de los pueblos de candomblé se expresan por medio del estómago) a las élites blanqueadas, nacionales e internacionales.

Esa interpretación está fuertemente anclada en lo que defiende Aníbal Quijano (2014). Ese importante autor sobre lo decolonial afirma que la categoría raza adquiere importancia y significación esenciales 
para el patrón mundial de poder capitalista, colonial/ moderno y eurocéntrico, pues la clasificación social universal del capitalismo se estableció y se reprodujo desde la atribución de nuevas identidades sociales y de la distribución de ellas en las relaciones de poder capitalistas: produjo nuevas relaciones intersubjetivas de dominación y estuvo en la base de una perspectiva de conocimiento mundialmente impuesta como la única racional. Eso porque los dominadores, 'europeos', fueron asociados a la raza 'blanca', y los dominados, los 'no europeos', fueron asociados a la raza 'no blanca'/ 'raza de color'/ 'negro'/ 'índio', y, en consecuencia, fueros construidos bajo las clasificaciones de 'superiores' e 'inferiores'. Eso en asociación con el control del trabajo, la "raza" justificó toda acción de dominación y explotación que vinieron con esas clasificaciones sociales (Quijano, 2014, pp. 318, 319).

El otro eje constitutivo del patrón mundial del capitalismo, para Quijano, se dio por medio de la distribución mundial del trabajo alrededor del capital. Parece redundante, pero ese autor explica que el capitalismo no prescinde de las otras relaciones sociales de trabajo y, la verdad, organiza la explotación del trabajo alrededor de un complejo mecanismo mundial, cuyo centro era la relación capital-salario. Esa nueva forma de relación del trabajo convivía y era interdependiente de todas las demás (esclavitud, servidumbre, producción mercantil simples, reciprocidad; Quijano, 2014, p. 320).

Ese patrón histórico-estructural del capitalismo era, por lo tanto, heterogéneo, ya que se articulaba en torno de la relación de poder central las otras relaciones históricamente construidas y heterogéneas entre sí. En asociación con el primer eje, el de la racialidad, las relaciones de control del trabajo fueron racialmente divididas, de manera que principalmente la esclavitud y la servidumbre fueron "naturalmente" destinadas a los pueblos inferiorizados, a las 'razas de color', a los negros e indígenas. Por otro lado, la asociación de las identidades raciales de los colonizados con las relaciones de control de trabajo no pagado hizo que los europeos percibieran que a ellos estaría "naturalmente" atribuido el privilegio del trabajo asalariado (Quijano, 2014, p. 781).

Así, la "colonialidad del poder" es la categoría creada por Quijano para designar la trama de relaciones sociales de poder, racializadas, de explotación/ dominación/conflicto articuladas alrededor del trabajo (el eje central del patrón mundial capitalista se daba alrededor de relación capital-trabajo) y sus productos. Además del control del trabajo, otros ámbitos de la existencia fueron articulados en esa trama, de manera que, para el autor, también el "sexo, sus productos y la reproducción de la especie", "la naturaleza y sus recursos de producción", "la subjetividad y sus productos materiales e intersubjetivos, incluso el conocimiento", y "la autoridad y sus instrumentos, de coerción en particular" se tornaron parte, constituyeron y fueron transformados y reconstituidos por ese nuevo patrón de relaciones sociales (Quijano, 2014, p. 289).

Si las relaciones de poder de control del trabajo tienen implicaciones sobre la intersubjetividad, también una intersubjetividad específica fue elegida $y$, por esto, es que las determinaciones, para el autor, no pueden ser unilineales ni unidireccionales. Son recíprocas, heterogéneas, descontinuas, inconsistentes y conflictivas. Por lo tanto, la estructura común de los ámbitos de la vida con las características descritas anteriormente, solo puede ser un campo de relaciones con las mismas atribuciones. Así, la colonialidad del poder es también del saber y del ser (Torres, 2007), al mismo tiempo en que es un campo de relaciones heterogéneo, descontinuo y conflictivo.

\section{Consideraciones finales}

Las propias baianas se afirmaron algunas veces por medio de categorías como 'mujeres', 'negras', 'trabajadoras', 'autónomas', 'independientes'. Ese vocabulario se utilizó en la mayoría de las veces para enmarcar las "diferencias" de las baianas de acarajé en relación con el mundo: hay baianos de acarajé, pero ellos probablemente aprendieron el oficio con las mujeres de su entorno comunitario; hay baianas de acarajé blancas, pero en la historia del oficio eran personas negras las que lo hacían; ser baiana de acarajé implica trabajar, trabajo que intermedia las relaciones de ellas con el mundo y las constituyen como independientes y autónomas, lo que las vuelve distintas de los otros trabajadores que están bajo las relaciones de intensa explotación del trabajo en función del capital. Esas diferencias son, a veces, clasificaciones predicadas por el ojo del colonizador, que vigila las relaciones interpersonales, como interpelaciones propias a ese ojo colonizador, como marcadores de alteridad. Por lo tanto, son diferencias construidas en procesos descontinuos, contextual e históricamente.

Otra importante categoría que apareció, implícita y explícitamente fue 'herencia': el oficio para las baianas era frecuentemente recordado como una herencia aprendida de sus ascendientes, una memoria 
de las remanecientes de un grupo de mujeres que vendían comidas en las calles, que transformaron la diferencia que el ojo colonial creó en diferencia para operar en las brechas del sistema colonial/moderno.

Por eso mismo, por medio de la amefricanidade, las baianas de acarajé cuestionan siempre las discriminaciones de género y raza a las que son sometidas: no aceptan ni caen en los discursos 'desarrollistas' de las élites, que reproducen racismo, sexismo y desigualdad. Además de eso, no se ven como víctimas; por el contrario, son y quieren ser agentes del turismo y de sus vidas.

Identifico también que hay la tentativa de transformarlas en logo marca de exportación, un atractivo que Brasil ofrece al mundo como mercadoría u objeto con valor de publicidad. Al cuestionar sobre ser vistas como 'baiana postal', las baianas reclaman ser signo vivo, luchan para no ser consideradas solamente como identidad política. La marca, el logo, es la identidad política globalizada, que se tiene que logotipar para conseguir algún recurso. Como signo es relacional, las baianas indican que no están en una chapa, como en una fotografía, sino en movimiento, en la dinámica de la historia, relacionándose con los otros (con Brasil y con el mundo) y con sí mismas, como alteridades históricas.

Como dije anteriormente aprendí con las baianas que su oficio significa un 'trabajo', realizado no solo con la finalidad económica a la que normalmente atribuimos cuando pensamos en esa categoría (como actividad destinada a proporcionar medios de subsistencia). Para las baianas de acarajé, las relaciones de comercio que ellas establecen y el trabajo que ellas realizan no tiene función capitalista, en el sentido de la acumulación y explotación. El trabajo tiene dimensión constitutiva de sus subjetividades, en el sentido de que esa dimensión de sus vidas no tiene la misma función que normalmente el trabajo adquiere para otras personas, cambiado en las relaciones capitalistas por salario. El comercio también es constitutivo del oficio, ya que no se trata solamente de vender el acarajé -si así fuera, el acarajé sería una mercancía más en el mercado-.

Finalmente, importa decir que ser comerciante para las baianas de acarajé significa relacionarse con el mundo de una manera muy propia, con varios significados simbólicos, culturales, religiosos, entre los cuales la reproducción y la perpetuación de una herencia afrobrasilera. Uno de los significados, por ejemplo, se relaciona con la oferta de vida, de amor, de bien-estar y de renuncia a la usura, una vez que la expresión de los sentimientos se da por el estómago. Me explicaron, por fin, que además cuando se es pobre, siempre se deja un poco para devolver a la naturaleza, porque ella comparte el mundo con nosotros; lo que sobra en el plato vuelve para realimentar la naturaleza.

\section{Referencias}

Cardoso, C. (2012). Outras falas: feminismos na perspectiva de mulheres negras brasileiras (Tesis de doctorado). Salvador: PPGNEIM/UFBA.

Fedération Interlationale de Footbal Association (FIFA). (2012). Invitation to tender for the rights of the FIFA Food \& Beverage Concessionaire Programme Phase I. Zurich, Switerzland, 30 jan. 2012. Disponible en $<$ http://www.fifa.com/mm/document/tournament/ loc/01/57/49/58/phase1ofitt2014.pdf $>$. Acceso 23 de mayo de 2015.

González, L. (1988). A categoria político-cultural de amefricanidade. Tempo Brasileiro, 92(93), 69-82.

IPHAN. (2007). Ofício das Baianas de Acarajé. Brasília: IPHAN.

Machado, T. (2013). De dendê e baianidade -a construção de um bem cultural denominado comida baiana. Revista Brasiliense de Pós-Graduação em Ciências Sociais, 12(1), 239-266.

Quijano, A. (2014). Cuestiones y horizontes: de la dependencia histórico-estructural a la colonialidad/descolonialidad del poder. D. Clímaco (Comp.). Buenos Aires: Clacso.

Santos, L. (2008). O corpo, o comer e a comida: um estudo sobre as práticas corporais e alimentares no mundo contemporâneo [online]. Salvador: Edufba.

Santos, V. J. (2013). O sincretismo na culinária afro-baiana: o acarajé das filhas de iansã e das filhas de jesus. Salvador: Universidade Federal da Bahia.

Segato, R. (2005). Santos e daimones (2a ed.). Brasília: UNB.

Segato. R. L. (2012). Gênero e colonialidade: em busca de chaves de leitura e de um vocabulário estratégico descolonial. E-cadernos CES, (18), 106-131. http://dx.doi. org/10.4000/eces. 1533

Segato, R. L. (2013). Ejes argumentales de la perspectiva de la colonialidad del poder. Revista Casa de las Americas, (272), 17-39.

Segato, R. L. (2013a). La escritura en el cuerpo de las mujeres asesinadas en Ciudad Juárez. Buenos Aires: Tinta Limón. 
Segato, R. L. (2015). La pedagogía de la crueldad. Revista Página 12. Recuperado de <http://www.pagina12. com.ar/diario/suplementos/las12/13-9737-2015-0529.html>, acceso en 20 abr. 2016.

Torres, G. M. (2007). Baiana do Acarajé: A uniformização do típico em uma tradição culinária afro-brasileira (Doutorado em Antropologia). Universidade de Brasília, Brasília.

Torres, M. (2007). Sobre la colonialidad del ser: contribuciones al desarrollo de un concepto. En S. Gómez y R. Grosfoguel (Comp.), El giro decolonial: reflexiones para una diversidad epistémica más allá del capitalismo global. Bogotá: Siglo del Hombre Editores. 